05,01

\title{
Влияние текстуры на ширину доменов в спеченных магнитах (PrDy)(FeCo)B и (NdDy)(FeCo)B
}

\author{
(C) А.И. Безверхний ${ }^{1}$, О.В. Коплак ${ }^{1}$, Р.А. Валеев ${ }^{2}$, Д.В. Королев ${ }^{2}$, В.П. Пискорский ${ }^{2}$, Р.Б. Моргунов ${ }^{1,2}$ \\ ${ }^{1}$ Институт проблем химической физики РАН, \\ Черноголовка, Россия \\ ${ }^{2}$ Всероссийский институт авиационных материалов, \\ Москва, Россия \\ E-mail: morgunov2005@yandex.ru
}

Поступила в Редакцию 19 июня 2019 г.

В окончательной редакции 19 июня 2019 г.

Принята к публикации 24 июня 2019 г.

Проведен анализ изображений магнитной силовой микроскопии поверхности образцов, вырезанных параллельно и перпендикулярно текстуре, созданной приложением поля в процессе прессования магнита. Обнаружено, что распределение линейного размера (ширины) доменов коррелирует с распределением площади проекции зерен на плоскость среза в спеченных магнитах $(\mathrm{PrDy})(\mathrm{FeCo}) \mathrm{B}$ с радиальной намагниченностью и в призматических магнитах $(\mathrm{NdDy})(\mathrm{FeCo}) \mathrm{B}$. Обсуждается влияние размера зерен и направления осей легкого намагничивания зерен на ширину доменов, как основных факторов, управляющих доменной структурой.

Ключевые слова: доменные стенки, домены, редкоземельные спеченные магниты.

DOI: 10.21883/FTT.2019.11.48411.523

\section{1. Введение}

Совершенствование свойств постоянных магнитов одна из наиболее актуальных тематик, на которую направлены значительные силы и средства мирового научного сообщества [1]. Традиционная схема создания редкоземельных магнитов обычно включает: 1) процесс изготовления, варьирующий химический состав и режимы термообработки и прессования магнитов, 2) процесс анализа магнитных свойств, как правило, сводящийся к определению коэрцитивной силы $H_{c}$, намагниченности насыщения $M_{s}$ и остаточной намагниченности $M_{r}$. В литературе имеется относительно небольшое количество работ, в которых бы упомянутые выше характеристики связывались с доменной структурой образца. Как правило, вариации основных характеристик магнита при изменении условий его приготовления a priori относят к изменению фазового и химического состава магнита. Можно привести большое количество примеров, когда лишь параметры $H_{c}, M_{s}$ и $M_{r}$ рассматриваются в качестве отклика на изменение химического состава магнита. Случаи одновременного сопоставления параметров доменной структуры с остальными характеристиками редки. Вместе с тем именно доменная структура определяет конечные магнитные свойства спеченного магнита. Доменная структура может изменяться не потому, что поменялся химический или фазовый состав. Она также зависит от дефектов, играющих роль центров закрепления доменных стенок, от баланса магнитостатических полей, которые определяются размером и формой зерен, а также параметрами межзеренных пространств [2-4]. Одним из главных факторов, управляющих доменной структурой магнита, является текстурирование его зеренной структуры в процессе прессования. Помещение магнитных микрочастиц в постоянное магнитное поле в процессе прессования магнита задает преимущественную ориентацию легких осей намагничивания зерен в готовом изделии (рис. 1). В частности, таким образом создаются кольцевые магниты с радиальной намагниченностью (рис. 1) или более простые анизотропные магниты в форме призмы. Анализ их доменной структуры в данной работе осуществляли с помощью магнитной силовой микроскопии (MCM).

Два типа магнитов (PrDy)(FeCo)B и (NdDy)(FeCo)B были выбраны потому, что, в отличие от $\mathrm{NdFeB}$, обладают значительно лучшей стабильностью по температуре и по времени, как это было показано в серии наших предыдущих работ [1-7]. Они позволяют создавать кольцевые магниты с радиальной намагниченностью и другие сложные типы магнитов, используемые в промышленности. При этом магниты (PrDy) (FeCo)B и (NdDy) (FeCo)B несколько проигрывают $\mathrm{NdFeB}$ в, так называемых, „основных“ свойствах $H_{c}, M_{s}$ и $M_{r}$. С точки зрения анализа полученных данных выбранная пара магнитов обеспечивала различия магнитной анизотропии, достаточной для того, чтобы в одном типе образцов наблюдалась намагниченность „в плоскости“ пластинки, тогда как в образцах с призматической формы наблюдалась наклонная намагниченность по отношению к поверхности образца. Ранее для образца $(\mathrm{Nd} \mathrm{Dy})_{16.2}(\mathrm{FeCo})_{78.1} \mathrm{~B}_{5.7}$ была иссделованна ширина доменых стенок [4]. Было установлено, что ширина доменной стенки составляет $3 \mathrm{~nm}$, и она не изменяется значительно в серии магнитов со схожим составом. 


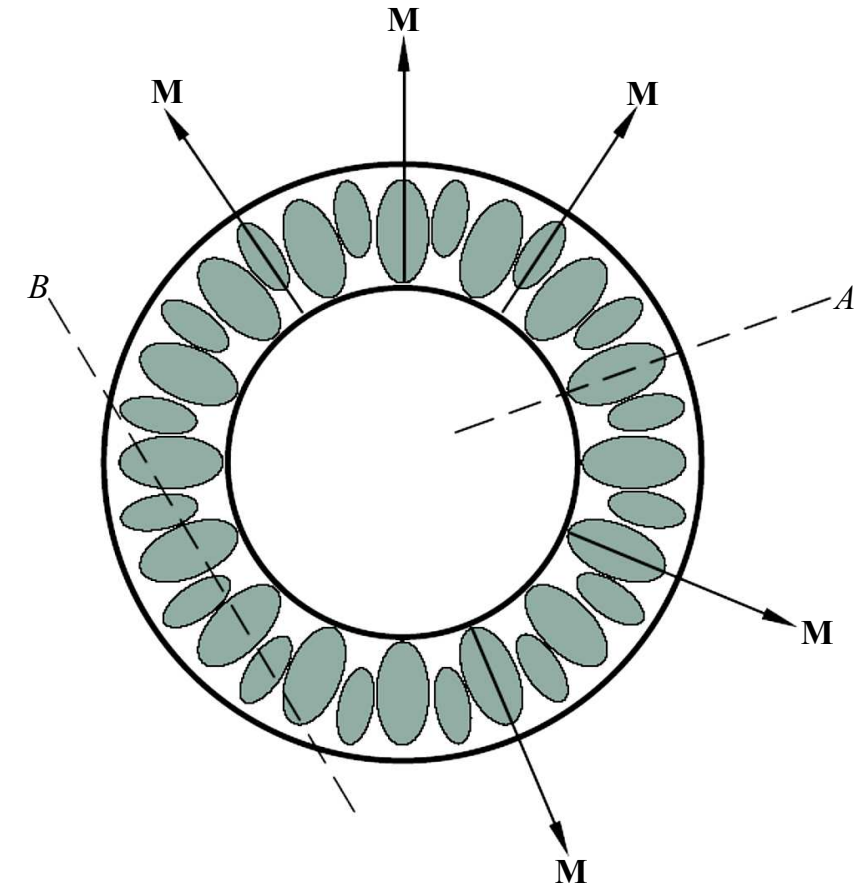

Рис. 1. Эскиз сечения радиально текстурированного кольца $(\mathrm{PrDy})(\mathrm{FeCo}) \mathrm{B}$ с изображением ориентаций главных осей намагниченности зерен, показанных векторами М. Два варианта изготовления тонкой пластинки показаны секущими линиями: $A-$ вдоль зеренной текстуры, $B-$ перпендикулярно текстуре.

Цель настоящей работы заключалась в анализе распределения ширин самих доменов в зависимости от ориентации плоскости МСМ сканирования поверхности по отношению к направлению оси легкого намагничивания спеченного магнита, заданного текстурированием зерен образца в процессе прессования в магнитном поле.

\section{2. Методика}

Образцы $(\mathrm{PrDy})_{13}(\mathrm{FeCo})_{79} \mathrm{~B}_{8}$ в виде радиально намагниченных колец внешним диаметром $25 \mathrm{~mm}$ и внутренним диаметром $20 \mathrm{~mm}$, а также призматические образцы $(\mathrm{Nd} \mathrm{Dy})_{16.2}(\mathrm{FeCo})_{78.1} B_{5.7}$. Из обоих типов спеченных магнитов вырезали одинаковые пластинки размером $1 \times 3 \times 5 \mathrm{~mm}$. Магниты были получены путем спекания предварительно спрессованной заготовки из порошка с размерами исходных частиц менее $10 \mu \mathrm{m}$ в высокотемпературной вакуумной печи. Методика получения, а также химический и фазовый анализ подробно описаны в работе [5].

Изображения доменной структуры образцов были получены с помощью атомного силового микроскопа AistNTSmartSPM (MFM) в отсутствие магнитного поля. Измеряемые значения магнитной силы, пропорциональные градиенту магнитного поля вблизи поверхности образца, были также пропорциональны частотному сдвигу вибрирующего кантилевера на основе $\mathrm{CoCr}$ с коэрцитивной силой 400 Ое в режиме „tapping-lift“. Силовая константа и резонансная частота кантилевера были равны $5 \mathrm{~N} / \mathrm{m}$ и $50 \mathrm{kHz}$ соответственно. Расстояние кантилевера от поверхности составляло $Z=80 \mathrm{~nm}$, и было одинаковым во всех опытах.

Динамический метод магнитно-силовой микроскопии, как и статический, является двухпроходной методикой. Он отличается от статического тем, что кантилевер колеблется с резонансной частотой во время второго прохода. По результату измерения амплитудно-фазовых и фазово-частотных характеристик кантилевера строится картина магнитных свойств поверхности. Данный метод позволяет получить более точные данные о распределении поверхностной намагниченности образца по сравнению со статическим методом. В методе динамической MCM измеряется производная магнитной силы $d F / d z$. Производная силы в приближении точечного диполя может быть представлена в виде:

$$
d F / d z=\mathbf{n} \operatorname{grad}(\mathbf{n F}),
$$

где $\mathbf{n}$ - единичный вектор нормали к плоскости кантилевера. Из этого выражения следует, что сигнал МСМ пропорционален второй производной вертикальной компоненты поля рассеяния $d^{2} H Z / d z^{2}$.

Сканирование поверхности было проведено дважды: в режиме атомного силового микроскопа (ACM) и магнитного силового микроскопа (МСM). Рельеф поверхности, полученный в режиме АCM (не показан) не совпадал с рельефом МСМ. Следовательно, измеряемый сдвиг фазы, который на рис. 2 передан оттенками серого цвета, пропорционален второй производной $d^{2} H Z / d z^{2}$ вдоль оси кантилевера $z$ и не связан с неровностями поверхности. На рис. 2 виден магнитный рельеф зерен, прослоек между ними и чередующихся темных и светлых полос внутри зерен. Эти полосы передают соответствующий рельеф магнитных доменов.

Отметим, что макроскопические магнитные характеристики, такие как, температурные зависимости намагниченности [6,7], петли гистерезиса $[4,6,7]$, магнитная релаксация [4], скачкообразное размагничивание [4] и многие другие свойства изучаемых в данной работе образцов были тщательно исследованы в наших предыдущих работах.

\section{3. Экспериментальные результаты}

На рис. 2 показаны результаты сканирования двух плоских образцов, вырезанных из одного и того же кольца спеченного магнита (PrDy)(FeCo)B параллельно линиям $A$ и $B$ на рис. 1. Для образца $A$ было проведено два измерения МСМ после его намагничивания и после размагничивания. Для образца $B$ было проведено одно измерение. Из рис. 2 видно, что доменная структура в сечении $A$ представляет собой короткие и довольно узкие полоски неправильной формы. В сечении $B$ доменная структура более контрастна, домены имеют большую 

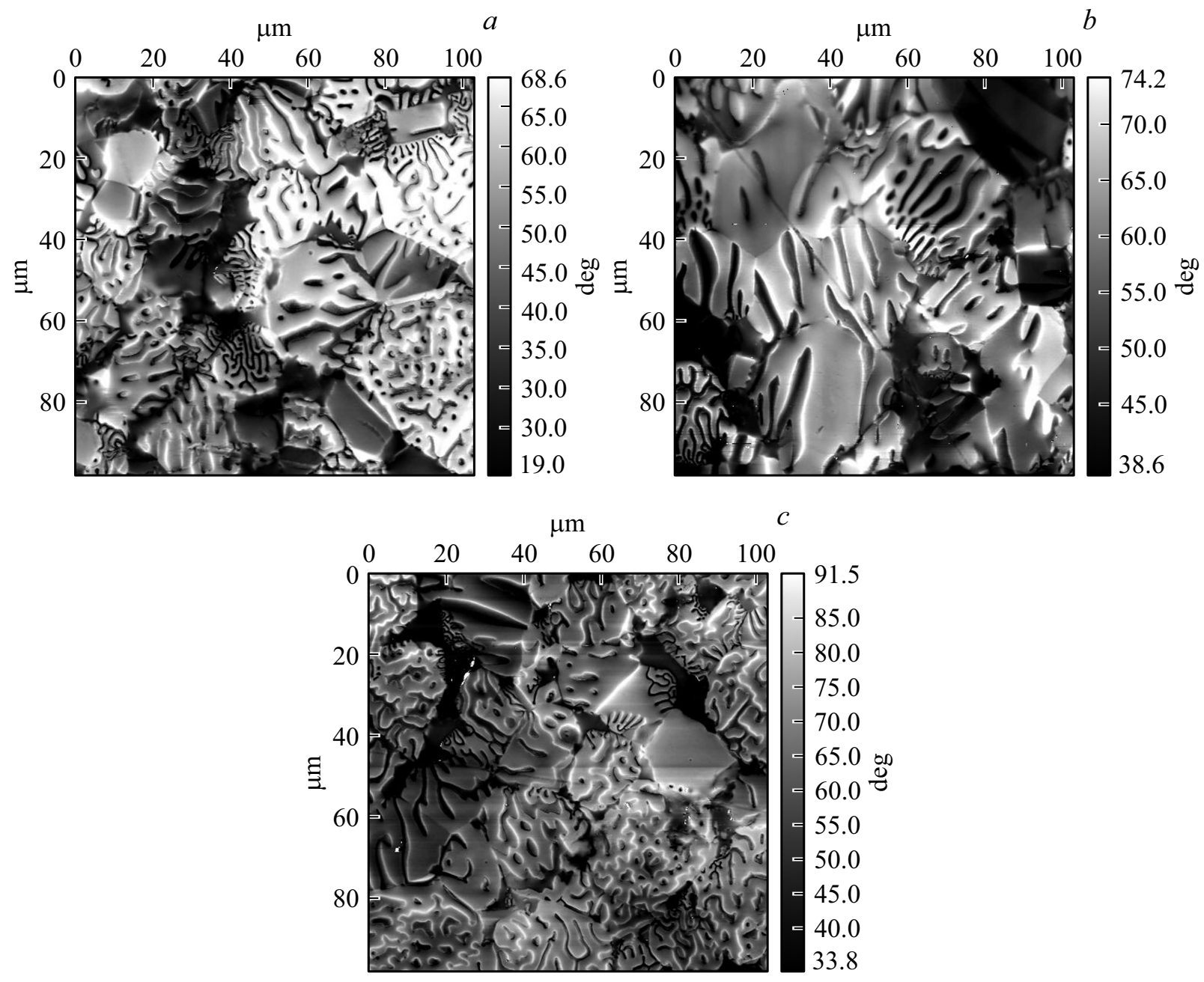

Рис. 2. Типичные изображения, полученные магнитным силовым микроскопом на поверхностях предварительно намагниченных образцов $(\mathrm{PrDy})(\mathrm{FeCo}) \mathrm{B}$ : с ориентацией $A(a)$ и с ориентацией $B(b)$. Изображение $(c)$ соответствует размагниченному образцу с ориентацией $A$.

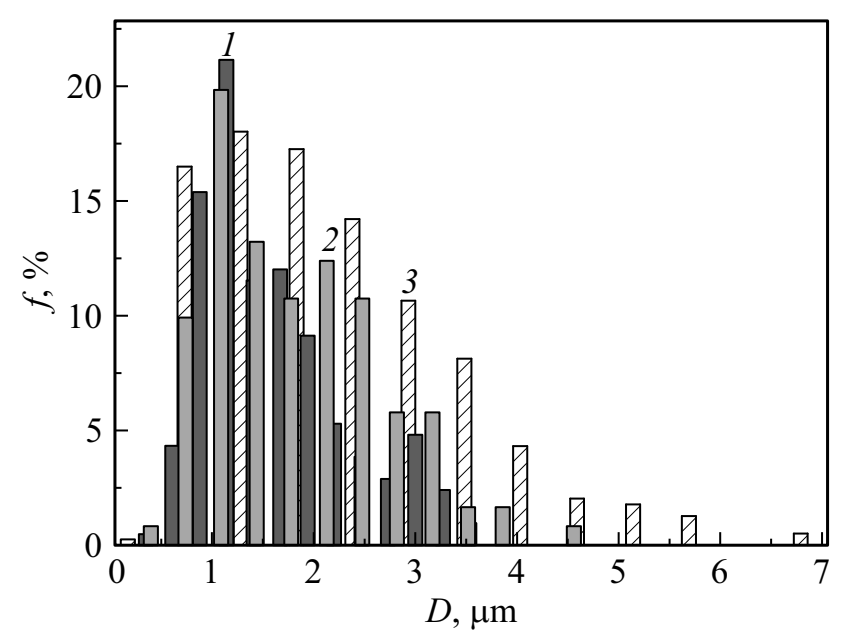

Рис. 3. Распределения ширин доменов в намагниченном образце $(\mathrm{PrDy})(\mathrm{FeCo}) \mathrm{B}$ с ориентацией $A(1)$, в размагниченном образце с ориентацией $A(2)$, в намагниченном образце с ориентацией $B(2)$.

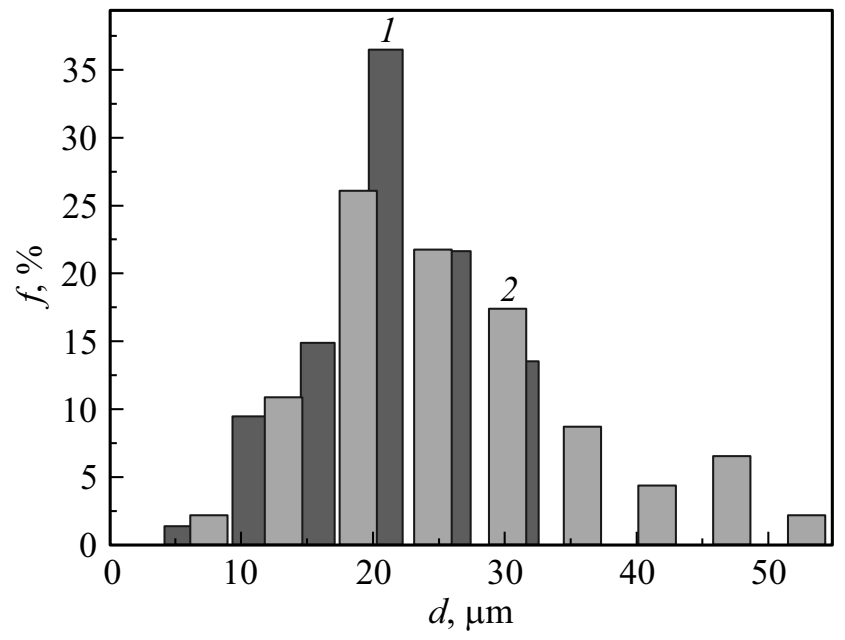

Рис. 4. Распределения линейного размера зерен для сечений с ориентацией $A(1)$ и с ориентацией $B(2)$. 
ширину. Для получения количественной характеристики ширин доменов выбиралось несколько направлений, приблизительно перпендикулярных большинству доменов, и вдоль этих прямых последовательно измеряли ширину каждого домена $D$. При этом набирали представительную статистику из 50-60 измерений. Результаты измерений представлены на рис. 3 в виде гистограмм распределения частот $f$, с которыми ширины доменов попадают в заданный интервал $\Delta D$. Видно, что для образца, вырезанного по сечению $A$, полученное распределение не зависит от его намагничивания и размагничивания. С одной стороны, это говорит о хорошей воспроизводимости полученных гистограмм и достаточной статистике измерений. С другой стороны, свидетельствует о том, что остаточная намагниченность образца после отключения поля близка к размагниченному состоянию и доменные структуры в этих состояниях почти не отличаются (ср. рис. 3, $a$ и $c$ ). Из сравнения рис. 2, $a$ и $b$ видны значительные отличия в распределении ширины доменов между образцами, вырезанными по сечениям $A$ и $B$. Эти изменения в сечении $B$ заключаются в наличии доменов с меньшей и большей шириной, которые делают распределение более широким, оставляя при этом наиболее вероятное значение там же, что и в сечении $A$.

Поскольку ширину доменов в спеченных магнитах в литературе принято связывать с размером зерен, нами было построено также распределение по размерам зерен в сечениях $A$ и $B$ (рис. 4 ). Из рис. 4 видно, что в сечении $B$ распределение размеров зерен является более широким из-за наличия зерен, больших по размеру, чем в сечении $A$. Таким образом, при сканировании магнитного рельефа в плоскости перпендикулярной главным осям намагниченности (направление $A$ ) получаются меньшие ширины доменов и наблюдаются меньшие размеры сечений зерен, чем при сканировании рельефа в плоскости, параллельной главным осям намагниченности зерен (направление $B$ ).

Для того, чтобы оценить степень общности данного вывода, нами были выполнены аналогичные опыты для редкоземельного спеченного магнита другого состава $(\mathrm{NdDy})(\mathrm{FeCo}) \mathrm{B}$ и другой формы в виде призмы. На рис. 5 показаны результаты сканирования трех разных плоскостей одного и того же образца, показанных схематично под каждой фотографией. Видно, что при сканировании в плоскости, параллельной главной оси намагниченности зерен, наблюдаются продолговатые длинные домены в виде полос (показаны стрелками на рис. $5, a, b)$. При сканировании в плоскости, перпендикулярной главным осям намагниченности зерен, наблюдаются короткие закругленные домены малой ширины. Таким образом, в спеченных редкоземельных магнитах другого состава и формы наблюдается такая же закономерность, как и для кольцевых магнитов: увеличение линейного размера сечений зерен ведет к росту ширины доменных стенок.

\section{4. Обсуждение}

Перемагничивание спеченных магнитов, исследуемых в настоящей работе, определяется движением доменных стенок и размножением зародышей обратной намагниченности внутри зерен. Перемагничивание однодоменных частиц, подчиняющихся закономерностям Нееля-Брауна, не дает вклада в петли гистерезиса в исследуемых материалах. Об этом свидетельствует малый предельный размер сферической однодоменной частицы образца $(\mathrm{NdDy})(\mathrm{FeCo}) \mathrm{B}[8]$ :

$$
r_{\mathrm{cr}}=\left(2 / M_{S}\right) \sqrt{(3 A) /(4 \pi)}=13 \mathrm{~nm},
$$

где $M_{S}=637 \mathrm{emu} / \mathrm{cm}^{3}$ намагниченность насыщения, $A=6.7 \cdot 10^{-7} \mathrm{egr} / \mathrm{cm}$ константа обменного взаимодействия, установленные в [4] для $(\mathrm{NdDy})(\mathrm{FeCo}) \mathrm{B}$. Средний размер зерен $\sim 20 \mu \mathrm{m}$ на три порядка величины превышает предел однодоменности. Частицы с таким размером не встречаются в распределении, и перемагничивание нужно рассматривать как изменение доменной структуры.

Решающее значение для определения направления намагниченности ферромагнитной пластинки играет разность полей магнитокристаллической анизотропии $H_{m}=2 K / M_{s}$ и анизотропии формы $H_{\text {shape }}=4 \pi M_{s}$. Направление намагниченности предопределено разностью вкладов магнитной анизотропии и поля размагничивания $2 K / M_{s}-4 \pi M_{s}$. Для исследуемых нами текстурированных образцов $(\mathrm{PrDy})(\mathrm{FeCo}) \mathrm{B}$, в которых направление оси легкой намагниченности зерен в основном перпендикулярно пластинке (ориентация $A$, рис. 1) выполняются неравенства $2 K / M_{s}>0$ и $2 K / M_{s}-4 \pi M_{s}<0$. Поэтому для таких образцов ось анизотропии лежит перпендикулярно плоскости пластинки, но легкая ось намагничивания лежит в плоскости пластинки, из-за того, что эта анизотропия подавлена полем размагничивания. Для образцов с ориентацией $B$ (рис. 1) $K / M_{s}<0$ и $2 K / M_{s}-4 \pi M_{s}<0$, так что ось анизотропии и легкая ось намагниченности также лежат в плоскости тонкой пластинки. Таким образом, независимо от направления среза, тонкие пластинки исследуемых ферромагнетиков $(\mathrm{PrDy})(\mathrm{FeCo}) \mathrm{B}$ были намагничены в плоскости. На это обстоятельство указывает также полосовая структура доменов, форма которых не зависит от ориентации, в которой была вырезана пластинка (рис. 3). Несмотря на одинаковую направленность намагниченности в пластинках разных ориентаций, доменная структура отличается в них лишь количественно.

Иначе обстоит дело в призматических образцах $(\mathrm{NdDy})(\mathrm{FeCo}) \mathrm{B}$, в которых доля анизотропии формы мала, и „побеждает“ анизотропия, связанная с преимущественной ориентацией главных осей намагничивания зерен. В таких образцах наблюдается значительное различие доменной структуры, которая представляет собой полосы в плоскостях, параллельных главной оси намагничивания, и закругленные лепестки неправильной 

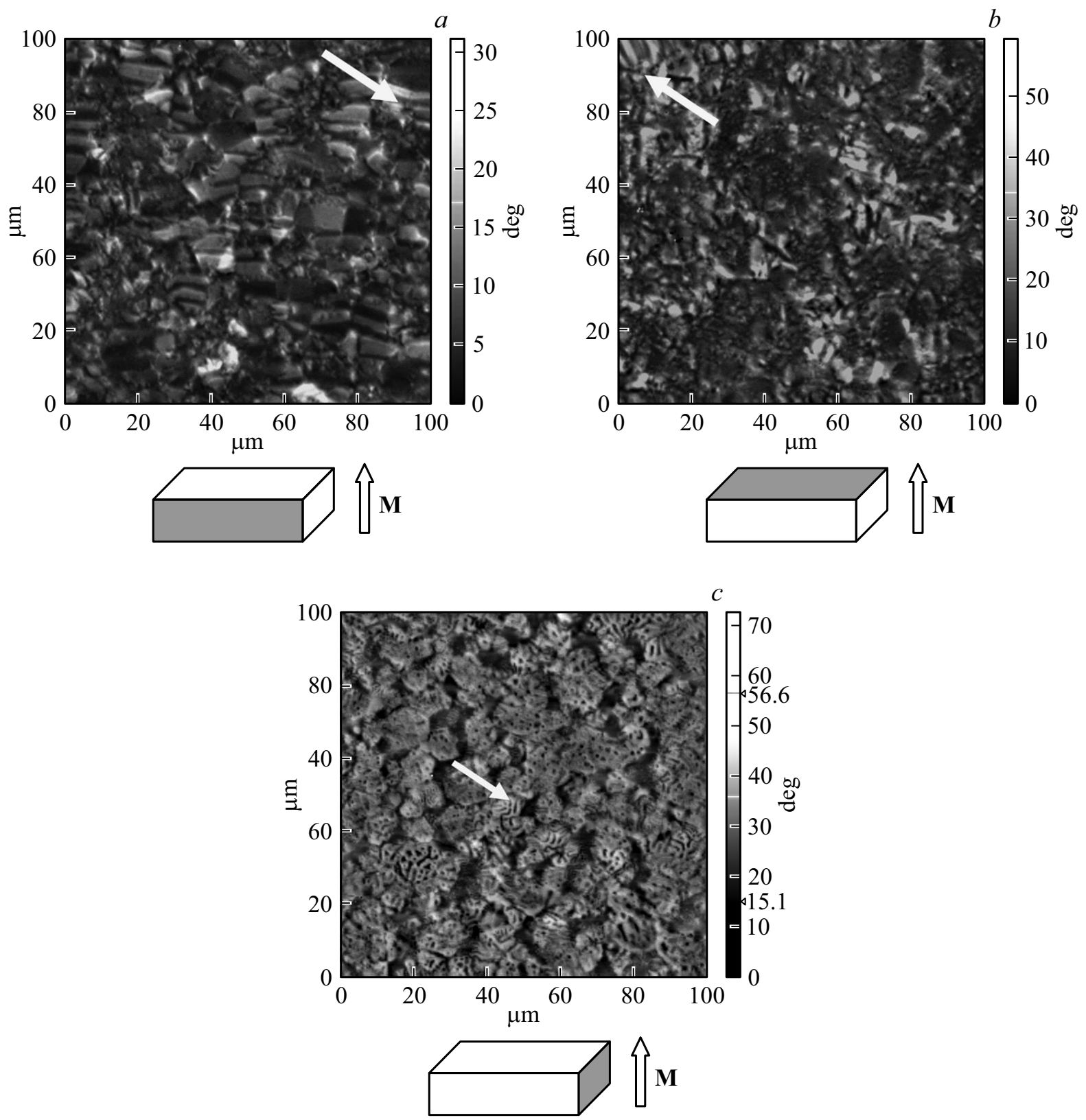

Рис. 5. Изображения $a-c$, полученные магнитным силовым микроскопом на поверхностях предварительно намагниченного призматического образца (NdDy)(FeCo)B. Поверхности, выбранные для сканирования, схематически показаны темным цветом под соответствующими изображениями МСМ. Стрелками показаны типичные домены для каждой из ориентаций. Стрелки под рисунками указывают направление намагниченности в образце.

формы в плоскости, перпендикулярной главной оси намагничивания (рис. 5).

Для объяснения различия формы доменов и их ширины в зависимости от ориентации вырезанной пластинки нужно учесть, что метод МСМ позволяет видеть лишь поверхностные домены, замыкающие магнитный поток в системе доменов, расположенных в объеме. Поэтому сканирование поверхности не дает представления о форме доменов в объеме образца, что достигается лишь специальной техникой, которой не было в нашем распоряжении [9].
Поверхностные клиновидные домены имеют обратную намагниченность. Их намагниченности, скорее всего отклонены от поверхности [10]. В случае редкоземельных магнитов энергия не может быть уменьшена до нуля путем образования замыкающих доменов вблизи поверхности из-за сильного магнитокристаллического поля анизотропии. Волнистость доменов вблизи поверхности увеличивается, если сканирование производится в плоскости, параллельной текстуре. Обычно амплитуда волнистости уменьшается постепенно с глубиной проникновения внутрь образца. Это уменьшает общую 
площадь доменных стенок на величину энергии, связанной с появлением магнитных полюсов. Причиной волнообразной формы доменов является сокращение магнитостатической энергии за счет увеличения общей площади доменных стенок Блоха.

Теория доменов предсказывает три режима зависимости ширины домена $D$ от линейного размера зерен $d$ : (1) При размере зерна до нескольких микрометров $D \sim d^{0.5}$ (режим 1 ); (2) При превышении размера зерна в несколько микрометров возникает явление разветвления доменов. Домены итеративно размножаются к поверхности образца, чтобы избежать появления магнитных полюсов на поверхности и уменьшить объем наиболее удаленных (неблагоприятно намагниченных) доменов, экономя при этом энергию доменных стенок в объеме. Ширина объемной области масштабируется с $D \sim d$ на несколько порядков размера зерна (режим 2); (3) Для очень больших размеров зерен, которые имеют место в нашей работе, снова наблюдается поведение $D \sim d^{0.5}[9,11]$ (режим 3, в котором преобладает магнитострикционная собственная энергия разветвленных приповерхностных доменов). Таким образом, рост ширины доменов на распределении рис. 3 можно объяснить также увеличением поперечного сечения размеров зерен на данной поверхности (рис. 4).

\section{5. Выводы}

Установлено, что наличие преимущественной ориентации зерен (текстуры) индуцирует разную доменную структуру на поверхностях тонких пластинок, вырезанных из кольцевых магнитов $(\mathrm{PrDy})(\mathrm{FeCo}) \mathrm{B}$, ориентированных параллельно и перпендикулярно осям легкой намагниченности зерен. Показано, что в пластинках $(\mathrm{PrDy})(\mathrm{FeCo}) \mathrm{B}$ главным управляющим фактором являются магнитные поля рассеяния зерен, которыми обусловлена зависимость ширины домена от размера зерна. В призматических магнитах $(\mathrm{NdDy})(\mathrm{FeCo}) \mathrm{B}$ с большой толщиной образца и большей магнитокристаллической анизотропией магнитостатическая энергия размагничивания поверхности уменьшается, что приводит к большему вкладу перпендикулярной намагниченности и появлению закругленных (не полосовых) доменов на поверхности, перпендикулярной направлению текстуры.

\section{Финансирование работы}

Работа поддержана Президиумом Российской академии наук: грант 18-030б, программа II, тема 1, „Наноструктуры: физика, химия, биология, основы технологий“

\section{Конфликт интересов}

Авторы заявляют, что у них нет конфликта интересов.

\section{Список литературы}

[1] В.П. Пискорский, Д.В. Королев, Р.А. Валеев, Р.Б. Моргунов, Е.И. Куницына. Физика и инженерия постоянных магнитов ВИАМ, М. (2018). 392 с.

[2] А.И. Дмитриев, В.В. Кучеряев, Е.И. Куницына, Р.А. Валеев, Р.Б. Моргунов, В.П. Пискорский, О.Г. Оспенникова, Е.Н. Каблов. ФТТ 58, 1530 (2016).

[3] А.И. Дмитриев, А.Д. Таланцев, Е.И. Куницына, Р.Б. Моргунов, В.П. Пискорский, О.Г. Оспенникова, Е.Н. Каблов. ЖЭТФ 150, 350 (2016).

[4] E. Kunitsyna, O. Koplak, V. Kucheryaev, R. Valeev, D. Korolev, V. Piskorskii, R. Morgunov. J. Appl. Phys. 124, 163906 (2018).

[5] E.N. Kablov, O.G. Ospennikova, E.A. Davydova, A.V. Buzenkov, R.A. Valeev, R.B. Morgunov, V.P. Piskorskii. Rus. Metallurgy (Metally) 2018, 243 (2018).

[6] E.N. Kablov, O.G. Ospennikova, V.P. Piskorskii, E.I. Kunitsyna, A.D. Talantsev, R.B. Morgunov. IEEE Trans. Magn. 52, 2102012 (2016).

[7] E.N. Kablov, O.G. Ospennikova, D.E. Kablov, V.P. Piskorskii, E.I. Kunitsyna, A.I. Dmitriev, R.A. Valeev, D.V. Korolev, I.I. Rezchikova, A.D. Talantsev, R.B. Morgunov. J. Appl. Phys. 117, 243903 (2015).

[8] У.Ф. Браун. Микромагнетизм / Пер. с англ. Наука, М. (1979). $160 \mathrm{c}$.

[9] I. Manke, N. Kardjilov, R. Schäfer. Nature Commun. 125, 1 (2010)

[10] Z.R. Zhang, B.S. Han, Y.Q. He, S.Z. Zhou. J. Mater. Res. 16, 2992 (2001).

[11] W. Szmaja. J. Magn. Magn. Mater. 153, 215 (1996).

Редактор Ю.Э. Китаев 